Article

\title{
An Experimental Study of Micro-Dimpled Texture in Friction Control under Dry and Lubricated Conditions
}

\author{
Yuan Wei ${ }^{1,2, *(D)}$, Jesus Resendiz ${ }^{3}$, Robert Tomkowski ${ }^{2}{ }^{D}$ and Xu Liu ${ }^{4, *}$ \\ 1 Frontiers Science Center for Flexible Electronics, Xi'an Institute of Flexible Electronics (IFE) and Xi'an Institute \\ of Biomedical Materials \& Engineering, Northwestern Polytechnical University, Xi'an 710072, China \\ 2 Manufacturing and Metrology Systems, KTH Royal Institute of Technology, 10044 Stockholm, Sweden; \\ rtom@kth.se \\ 3 Department of Mechanical and Manufacturing Engineering, University of Calgary, \\ Calgary, AB T2N 1N4, Canada; jdjresen@ucalgary.ca \\ 4 School of Mechanical Engineering, Xi'an Aeronautical University, Xi'an 710077, China \\ * Correspondence: iamywei@nwpu.edu.cn (Y.W.); xu_liu@xaau.edu.cn (X.L.)
}

check for updates

Citation: Wei, Y.; Resendiz, J.;

Tomkowski, R.; Liu, X. An

Experimental Study of

Micro-Dimpled Texture in Friction

Control under Dry and Lubricated

Conditions. Micromachines 2022, 13,

70. https://doi.org/10.3390/

mi13010070

Academic Editors: Sunil Pathak and

Radhakrishnan Jagdheesh

Received: 16 December 2021

Accepted: 29 December 2021

Published: 31 December 2021

Publisher's Note: MDPI stays neutral with regard to jurisdictional claims in published maps and institutional affiliations.

Copyright: (C) 2021 by the authors. Licensee MDPI, Basel, Switzerland. This article is an open access article distributed under the terms and conditions of the Creative Commons Attribution (CC BY) license (https:/ / creativecommons.org/licenses/by/ $4.0 /)$.

\begin{abstract}
Friction control is a vital technology for reaching sustainable development goals, and surface texturing is one of the most effective and efficient techniques for friction reduction. This study investigated the performance of a micro-dimpled texture under varying texture densities and experimental conditions. Reciprocating sliding tests were performed to evaluate the effects of the micro-dimpled texture on friction reduction under different normal loads and lubrication conditions. The results suggested that a micro-dimpled texture could reduce the coefficient of friction $(\mathrm{CoF})$ under dry and lubricated conditions, and high dimple density results in a lower CoF. The dominant mechanism of the micro-dimpled texture's effect on friction reduction was discussed, and surface observation and simulation suggested that a micro-dimpled texture could reduce the contact area at the friction interface, thereby reducing CoF.
\end{abstract}

Keywords: laser surface texturing; micro dimples; dry friction; friction reduction

\section{Introduction}

Energy and material loss due to tribological contacts significantly affect energy consumption globally. Around $23 \%$ of the world's total energy consumption is used to overcome friction and to remanufacture contacting parts because of material loss [1]. Thus, minimizing friction in mechanical systems is vital for saving energy and reducing waste in our society. Using surface texture to reduce friction has become a focus of worldwide research. For decades, researchers have demonstrated that certain micro-textures minimize friction and wear. Several studies indicated that surface texture decreases the friction coefficient [2,3] and improves the lubrication condition of friction pairs by enhancing the hydrodynamic pressure effect [4]. Surface texturing techniques have been widely applied in several areas, such as cutting tools [5], bearings [6], cylinders [7], pistons [8], and rotating shafts [9].

A variety of techniques have been employed to fabricate surface texturing, including machine processing, chemical etching, electrical discharge machining, energy beam etching, and laser surface texture (LST). Laser surface texturing is a highly efficient, precise, versatile, and economical method to fabricate micro dimples and micro grooves compared to other texturing processes [10]. To date, significant improvements in surface texturing have been made in the past few decades. During the 1990s, Etsion et al. presented laser-textured spherical dimples on seal surfaces, which could theoretically enhance lubrication conditions [11], and the performance of the spherical dimple texture was verified experimentally the following year [12]. Pettersson et al. investigated the micro grooves under dry and lubricated conditions, and, under certain conditions, friction was reduced [13]. Numerous studies on surface texture 
have been published more recently. Wan et al. [14] reported that the coefficient of friction (CoF) was reduced by $80.1 \%$ due to a micro-dimpled texture under lubricated conditions, and Hao et al. found that friction decreased by $46.1 \%$ with linear grooves under lubricated conditions [15]. However, several studies reported an opposite effect; $\mathrm{Hu}$ et al. found that the CoF increased by $400 \%$ with circular dimples on a steel surface [16], and Dai et al. reported a 3.6\% increase in CoF with micro-dimple textured Ti-alloy surfaces [17]. Therefore, the conflicting reports in $\mathrm{CoF}$ trends in the literature indicate the uncertainty of the performance of LST texture, which is a challenge for further applications of LST texturing. Texture effects greatly rely on shape [18-20], size [21,22], and depth [23]. Other factors include density [24,25], area [26], and orientation [27] of the texture.

In general, surface texture can positively affect sliding surfaces, such as storing oil, catching debris, creating a hydrodynamic, pushing-up force, and reducing the contact area [28]. The performance of a micro-dimpled texture is determined by the combined effect of those mechanisms. However, under different solid contact conditions at the friction interface, the dominant mechanism changes. For instance, under hydrodynamic lubrication, which has no solid contact at the friction interface, surface texture can lead to an increase in load carrying capacity of the lubricant film [4]. Thus, lubrication conditions could be the main factor that determines the performance of surface textures. Consequently, more research is needed in the area of friction control using micro dimples under varying lubrication conditions.

In this study, the effect of micro-dimpled texture is investigated using reciprocating sliding tests under dry and lubricated conditions and varying normal loads. A pulsed laser with interval power output is used to fabricate the micro-dimpled texture. Experimental results suggested that the micro-dimpled texture significantly decreased $\mathrm{CoF}$ under both dry and lubricated conditions. The density of the micro-dimpled texture was proportional to the degree of friction reduction for all tested conditions. Furthermore, the mechanism of the micro-dimpled texture effect was discussed.

\section{Texture Preparation}

In this study, the micro-dimpled texture was produced using a commercial laser marking system. The schematic diagram of the system is shown in Figure 1, and the specifications are listed in Table 1. A laser beam passed through a galvanometer scanner and a field lens and then irradiated the workpiece surface directly. The scanner could quickly adjust the position of the laser beam using a two-axis mirror galvanometer system. The laser beam had a nearly Gaussian profile (>95\%).

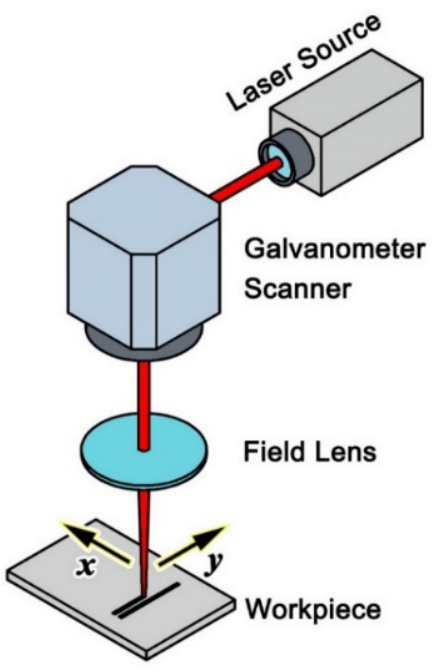

Figure 1. Schematic diagram of the laser marking system. 
Table 1. Specifications of the laser marking system.

\begin{tabular}{cc}
\hline Specifications & Target \\
\hline Laser type & Diode laser (Raycus ${ }^{\mathrm{TM}}$ RFL-P20Q) \\
Output power & $0-20 \mathrm{~W}$ \\
Wavelength & $1060 \mathrm{~nm}$ \\
Pulse frequency & $20-200 \mathrm{kHz}$ \\
Spot size & $50 \mu \mathrm{m}$ \\
Spot moving speed & $0-7000 \mathrm{~mm} / \mathrm{s}$ \\
\hline
\end{tabular}

AISI/ASTM 52100 bearing steel was selected as the workpiece material. The workpiece was machined as a cuboid with dimensions of $30 \mathrm{~mm} \times 15 \mathrm{~mm} \times 5 \mathrm{~mm}$. The contact surfaces, including the textured surface attached to the friction tester stage, were polished. The average surface roughness for the polished surfaces was $S_{a}=0.2 \mu \mathrm{m}$ and $S_{q}=0.3 \mu \mathrm{m}$. Heat treating was not performed on the workpieces. Micro-dimpled textures were fabricated on the workpiece surfaces, and the textured area was $450 \mathrm{~mm}^{2}$. During the texturing process, the laser output was set at $8 \mathrm{~W}$, the spot moving speed was $2000 \mathrm{~mm} / \mathrm{s}$, and the pulse frequency was $20 \mathrm{kHz}$.

The textured surfaces were observed using scanning electron microscopy (SEM), as shown in Figure 2. The micro dimples were arranged tightly in rows rather than in a uniform distribution across the workpiece surface, and two rows of micro dimples formed a textured belt. Three different textures were prepared, each with a different distance between the textured belt: $500 \mu \mathrm{m}, 300 \mu \mathrm{m}$, and $100 \mu \mathrm{m}$, and the dimple density for each were (a) $25.3 \%$ low density, (b) $36.2 \%$ medium density, and (c) $63.0 \%$ high density, respectively.
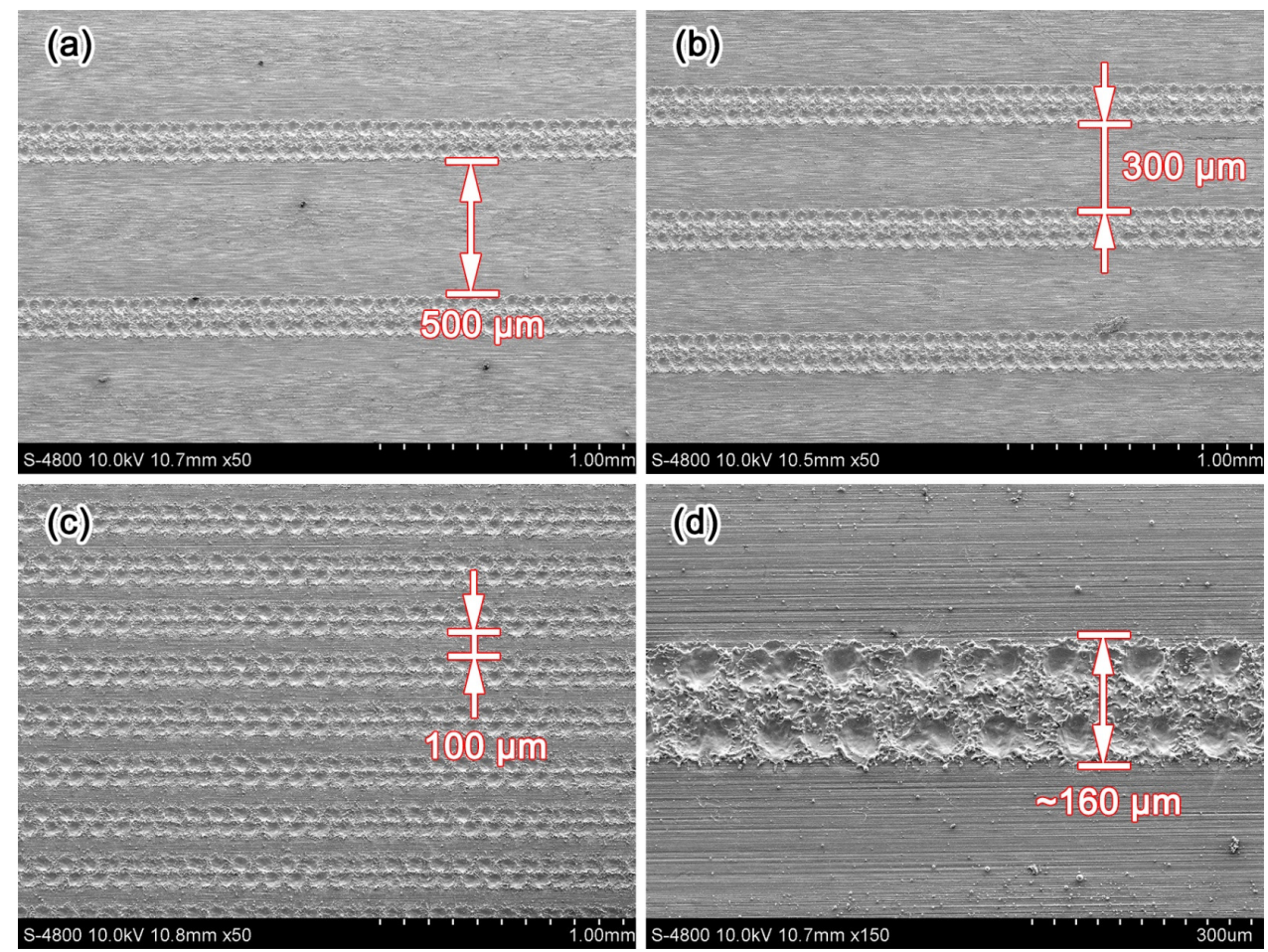

Figure 2. SEM images of the textured surfaces for dimple densities of (a) $25.3 \%$, (b) $36.2 \%$, (c) $63.0 \%$, and (d) partially enlarged dimples of $63.0 \%$.

\section{Reciprocating Sliding Test}

The effect of the micro-dimpled texture in tribological contacts has been evaluated using reciprocating sliding tests under both dry and lubricated conditions. The tests were performed using a homemade reciprocating friction tester. The experimental setup is shown in Figure 3. The workpiece was mounted on a three-component quartz table dynamometer. 
The force signals were collected by a data-acquisition system and recorded in a computer with a sampling rate of $1024 \mathrm{~Hz}$. The sliding motion was driven by a CNC linear motion stage. Sapphire $\left(\mathrm{Al}_{2} \mathrm{O}_{3}\right)$ was selected as the other material in the friction pair, and a $6 \mathrm{~mm}$-diameter sapphire half ball was mounted on the tester. The properties of sapphire are shown in Table 2. For the lubricated tests, SAE 0W30 engine oil was selected as the lubricant. The initial lubricant temperature was room temperature $\left(20^{\circ} \mathrm{C}\right)$, and $20 \mathrm{~cm}^{3}$ of engine oil was added to the sample pool (as shown in Figure 3c) before each test. The workpiece was immersed in the engine oil.

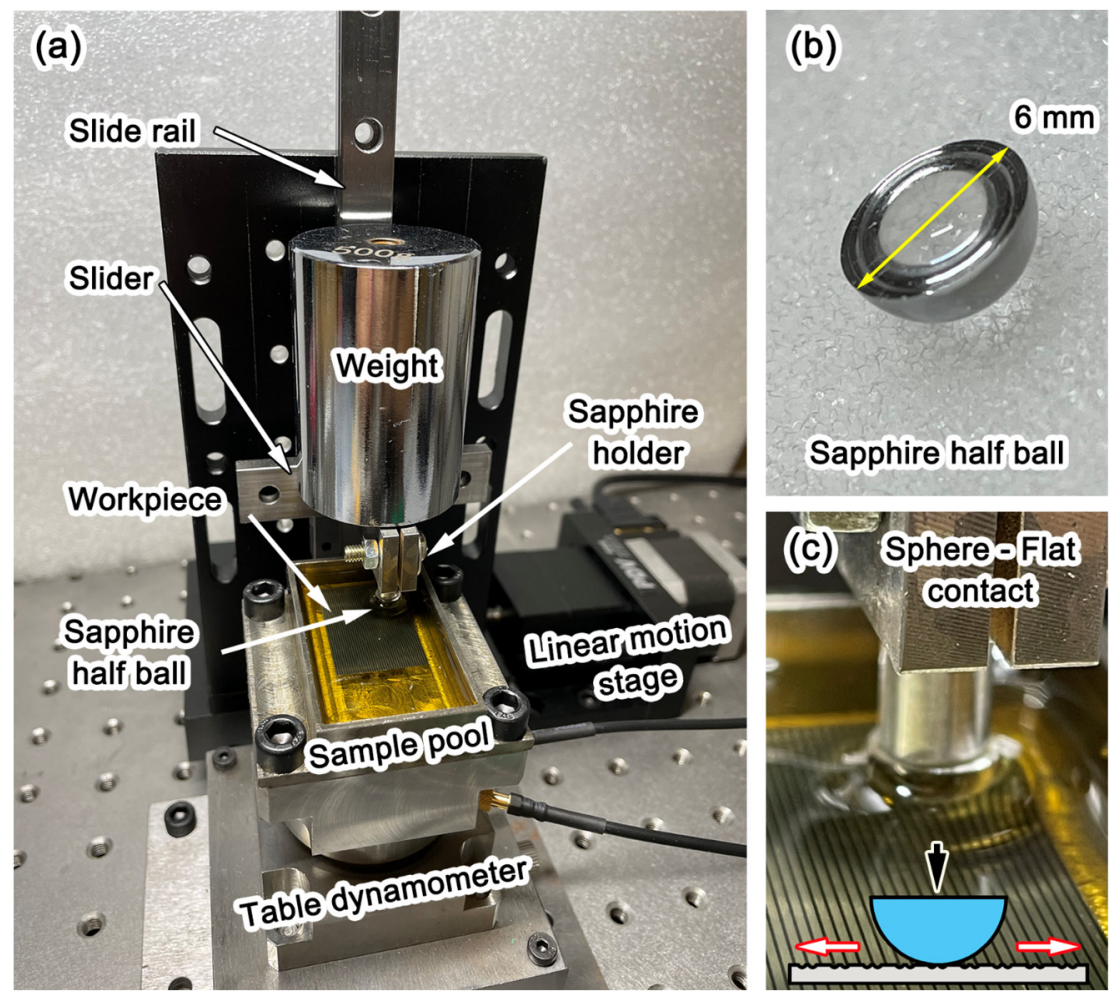

Figure 3. Experimental setup of the reciprocating sliding tests: (a) homemade reciprocating sliding friction test platform; (b) sapphire half ball; (c) sphere-flat contact.

Table 2. Physical properties of sapphire $\left(\mathrm{Al}_{2} \mathrm{O}_{3}\right)$ and AISI 52100 steel at room temperature.

\begin{tabular}{ccc}
\hline Properties & Sapphire & AISI 52100 Steel \\
\hline Density $\rho$ & $3910 \mathrm{~kg} / \mathrm{m}^{3}$ & $7810 \mathrm{~kg} / \mathrm{m}^{3}$ \\
Young's modulus $E$ & $345 \mathrm{GPa}$ & $200 \mathrm{GPa}$ \\
Poisson's ratio $v$ & 0.29 & 0.3 \\
Hardness, Vickers $H$ & 2300 & 700 \\
\hline
\end{tabular}

The homemade friction tester allowed a normal load to be applied using a standard weight. The sliding speed was $10 \mathrm{~mm} / \mathrm{s}$, the sliding distance was $15 \mathrm{~mm}$, and the sliding direction was perpendicular to the texture belts. The tester was calibrated before performing the test. A non-textured surface sample was prepared and tested as a reference. The average CoFs were obtained from 200 rounds of sliding under normal loads of $6.1 \mathrm{~N}, 8.5 \mathrm{~N}$, and $11.0 \mathrm{~N}$. The test results are presented in Figures 4 and 5 for the dry and lubricated tests, respectively. Zero percent on the $\mathrm{X}$-axis indicated the non-textured case as a reference. 


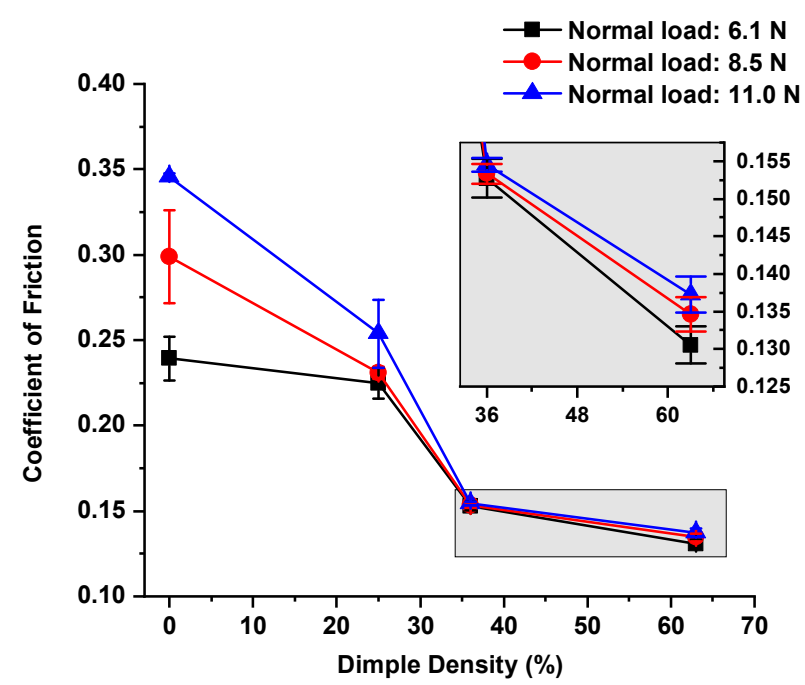

Figure 4. Comparison of $\mathrm{CoFs}$ in the non-textured case and textured cases under dry conditions and normal loads of $6.1 \mathrm{~N}, 8.5 \mathrm{~N}$, and $11.0 \mathrm{~N}$.

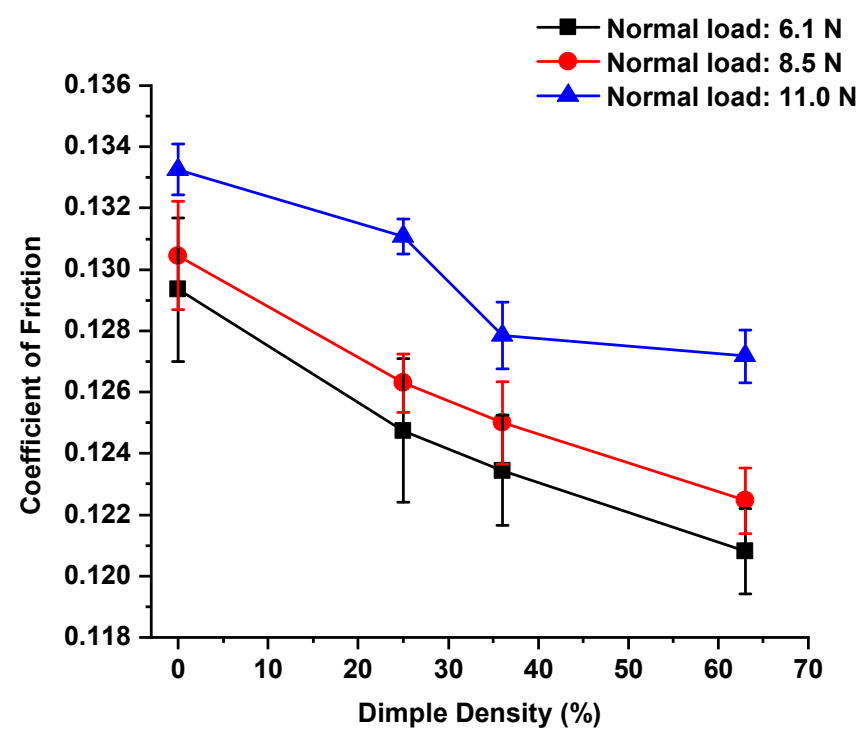

Figure 5. Comparison of $\mathrm{CoFs}$ in the non-textured case and textured cases under lubricated conditions and normal loads $6.1 \mathrm{~N}, 8.5 \mathrm{~N}$, and $11.0 \mathrm{~N}$.

Under dry conditions (Figure 4), the micro-dimpled texture significantly reduced the $\mathrm{CoF}$ compared to that observed in the non-textured case, especially for a normal load of $11.0 \mathrm{~N}$. The maximum friction reduction for normal loads of $6.1 \mathrm{~N}, 8.5 \mathrm{~N}$ and $11.0 \mathrm{~N}$ was $45.5 \%, 54.9 \%$, and $60.3 \%$, respectively. For medium $(36.2 \%)$ and high $(63.0 \%)$ densities, the $\mathrm{CoF}$ error bars corresponded to the overlap of different normal loads. Thus, the differences in the average CoF obtained from varying normal loads were minimized when higher dimple density was applied.

Under lubricated conditions (Figure 5), in general, the average CoF continuously decreased as dimple density increased for each normal load, especially for $6.1 \mathrm{~N}$ and $8.5 \mathrm{~N}$. The maximum friction reduction for normal loads of $6.1 \mathrm{~N}, 8.5 \mathrm{~N}$, and $11.0 \mathrm{~N}$ was $6.6 \%, 6.1 \%$, and $4.6 \%$, respectively. The degree of $\mathrm{CoF}$ reduction for normal loads of $6.1 \mathrm{~N}$ and $8.5 \mathrm{~N}$ was only slightly different.

\section{Contact Condition}

Contact surfaces are never "flat" when they come into contact; their roughness often causes the contact areas to be extremely small, which leads to high contact pressures and 
stresses, resulting in failure in the contact regions [29]. Contact mechanics between solid surfaces has been previously studied [30,31], and the literature concludes that the forces and deformations around a contact area between two pressed bodies play an important role in tribological interactions. Due to the limited range of speeds and loads that our tribometer could achieve, it was not possible to evaluate a full lubrication regime. However, considering the relatively slow speed and loads used in this study, the lubrication mechanism was in the boundary regime for the lubricated case. To verify this, the contact stresses could be calculated using the Hertzian contact equations (Equations (1) and (2)) [32]. The radius of the sphere of contact $a$ was related to the indenter applied normal force $F_{N}$, the indenter radius $R$, and the elastic properties of the materials:

$$
\begin{gathered}
a=\left(\frac{3 \cdot F_{N} \cdot R}{4 \cdot E^{*}}\right)^{\frac{1}{3}} \\
E^{*}=\left(\frac{1-v_{1}^{2}}{E_{1}}+\frac{1-v_{2}^{2}}{E_{2}}\right)^{-1}
\end{gathered}
$$

where $E^{*}$ is the reduced Young's modulus and $E_{1}, v_{1}$ and $E_{2}, v_{2}$ describe the elastic modulus and Poisson's ratio of the indenter and the specimen, respectively. The materials used in the experiments were AISI/ASTM 52100 bearing steel (workpiece) and a half-sphere sapphire (counter surface), and the material properties are listed in Table 2. The half-sphere sapphire was $6 \mathrm{~mm}$ in diameter. The maximum Hertzian contact pressure $P_{\max }$ was given by the indenter load divided by the projected contact area:

$$
P_{\max }=\frac{3 F_{N}}{2 \pi a^{2}}
$$

Table 3 shows the results of Hertzian contact analysis. The values obtained using Hertzian contact theory, used to estimate the maximum pressure beneath the sapphire sphere, ranged from 1390 to $1692 \mathrm{MPa}$ during friction measurements. The contact radius varied from $46 \mu \mathrm{m}$ to $56 \mu \mathrm{m}$, which was smaller than the width of the micro dimples. The yield stress of AISI/ASTM 52100 was $1410 \mathrm{MPa}$ [33].

Table 3. Contact pressures calculated using Hertzian analysis.

\begin{tabular}{cccc}
\hline Normal Force $\boldsymbol{F}_{\boldsymbol{N}}$ & $\mathbf{6 . 1} \mathbf{~ N}$ & $\mathbf{8 . 5} \mathbf{~}$ & $\mathbf{1 1 . 0 ~ \mathbf { ~ }}$ \\
\hline $\begin{array}{c}\text { Contact circular } \\
\text { radius } a\end{array}$ & $46 \mu \mathrm{m}$ & $51 \mu \mathrm{m}$ & $56 \mu \mathrm{m}$ \\
$\begin{array}{c}\text { Contact area } \\
\text { Max. Hertzian }\end{array}$ & $0.0079 \mathrm{~mm}^{2}$ & $0.0082 \mathrm{~mm}^{2}$ & $0.0098 \mathrm{~mm}^{2}$ \\
contact pressure $P_{\max }$ & $1390 \mathrm{MPa}$ & $1553 \mathrm{MPa}$ & $1692 \mathrm{MPa}$ \\
\hline
\end{tabular}

Surfaces begin to deform plastically when the magnitude of the mean contact pressure reaches values above $10 \%$ of the yield stress of the surface material that has the lowest hardness [30]. For applied loads of $8.5 \mathrm{~N}$ and $11 \mathrm{~N}$, the resultant stresses, approximated from Equation (3), were higher than the yield stress of the steel workpiece. However, the shearing action of the tip had not been considered. This analysis indicated that the contact area was under severe pressure, which caused plastic deformation of the steel workpiece. Consequently, it was highly probable that the lubricated tests were performed under the boundary lubrication regime, as predicted, because of the stresses and friction coefficients obtained during the reciprocation tests.

\section{Discussion}

The sliding test results suggested that the proposed micro-dimpled texture reduced friction under both lubricated and dry conditions using a relatively low sliding speed, particularly for dry conditions. The mechanism that allowed the dimples to reduce friction 
still needs to be discussed. Figure 6 shows the textured workpiece after the sliding tests with a normal load of $11.0 \mathrm{~N}$, in dry and lubricated conditions. The plastic deformation and wear marks were clearly visible. After 200 rounds of sliding, the basic surface profile of the dimples was retained, but the surface bulges around the dimples were worn down. According to the Bowden and Tabor theory [34,35], the friction force $F_{S}$ under lubricating conditions is expressed as follows:

$$
F_{S}=A_{r}\left\{\alpha s_{m}+(1-\alpha) s_{i}\right\}
$$
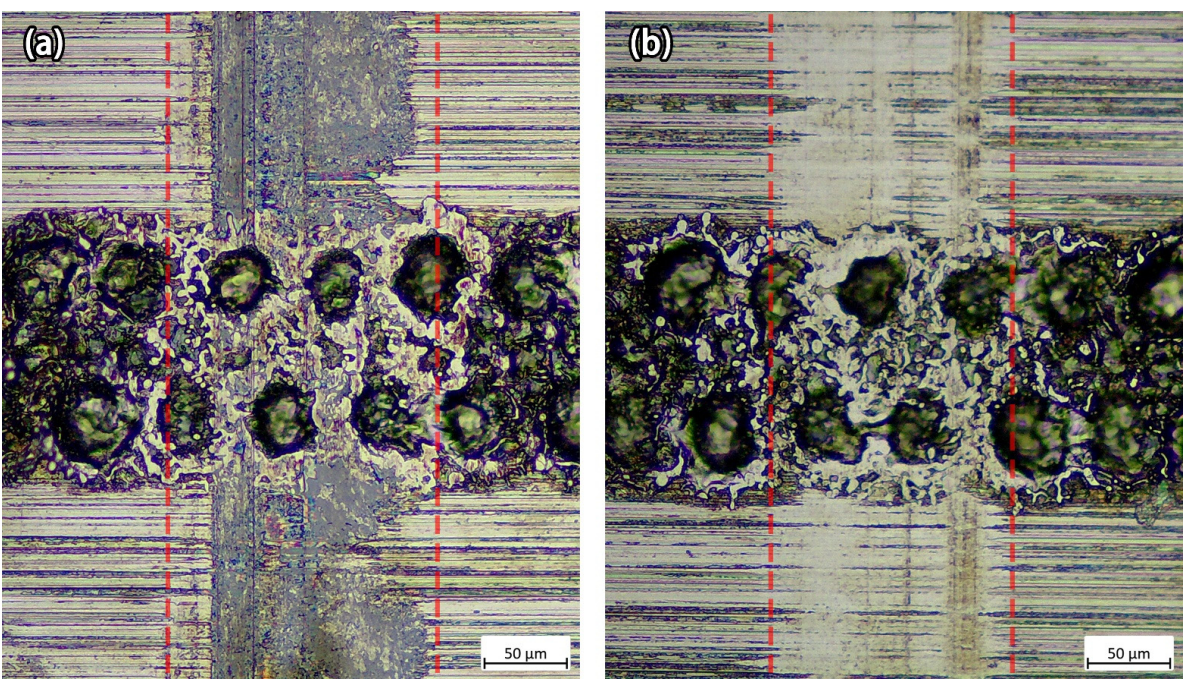

Figure 6. The textured workpiece after the sliding tests for both (a) dry and (b) lubricated conditions (normal load: $11.0 \mathrm{~N}$; dimple density: $63 \%$; magnification: $20 \times$ ).

For dry conditions, the friction force $F_{S}$ is as follows:

$$
F_{S}=A_{r} s_{m}
$$

where $A_{r}$ is the real contact area; $\alpha$ is the ratio of solid contact area due to the breakage of the lubricant film; $s_{m}$ is the shear strength of the solid at contact; and $s_{i}$ is the shear strength of the lubricant film. In the sliding tests, the only variable was the micro-dimpled texture for both dry and lubricated conditions. Therefore, it was possible to infer that the smaller solid-to-solid contact area, due to the micro-dimpled texture, resulted in less friction force compared to the friction force in the non-textured case. Furthermore, the total contact area along the contact path was reduced with more dimples, which may have explained the influence of dimple density on friction reduction, as shown in Figures 4 and 5. In addition, previous publications also suggested that texture could trap the micro-abrasive, further reducing friction $[13,36]$. That effect was not confirmed in this study, but it could still be one of the reasonable explanations for friction reduction.

The test results and surface observations of both dry and lubricated tests indicated that although the lubricant significantly minimized CoF, the dominant friction behaviour at the friction interface was still solid contact. Thus, the lubricated tests were performed under the boundary lubrication regime. There was no coherent lubricant film effect at the contact area. Simultaneously, the mechanism of the dimple effect may have been different between lubricated and dry conditions. In addition, in the sphere-flat contact, the lubricant flow domain showed a convergent shape due to the spherical shape of the sapphire and the flow space shrank gradually until reaching the contact area, which may have led to the generation of hydrodynamic pressure from the dimples or the convergent structure itself.

A computational fluid dynamics (CFD) model was designed based on the experimental setup to check the hydrodynamic pressure generation. A small flow area was chosen from the experimental setup. The flow area was $3 \mathrm{~mm}$ by $4 \mathrm{~mm}$, as shown in Figure 7 . The film 
thickness was set at $10 \mu \mathrm{m}$. The texture distribution in the model followed the experimental workpiece. The texture unit was designed based on a real dimple, which was fabricated on the workpiece, that had a diameter of $70 \mu \mathrm{m}$ and depth of $8 \mu \mathrm{m}$. The width of the texture belt was $160 \mu \mathrm{m}$. Figure 7a shows the flow domain of the CFD model, based on a high dimple density case under a normal load of $11.0 \mathrm{~N}$. The hole at the center of the flow domain indicated the contact area. The diameter of the hole was set based on the Hertzian contact calculation. In Figure 7a, the inlet and outlet indicate the fluid inflow boundary and outflow boundary of the CFD model, respectively. The inlet and outlet were defined as pressure-based; the operating pressure was set to 101,325 Pa. The bottom wall and two side walls were stationary; the translational motion was set so that the top sphere surface mimicked the relative motion of the friction pair, and the translational motion was set to $0.01 \mathrm{~m} / \mathrm{s}$. Based on the Hertz contact analysis, we assumed no coherent lubricant film was in the contact area. Thus, the contact area was excluded from the flow domain model.

(a)

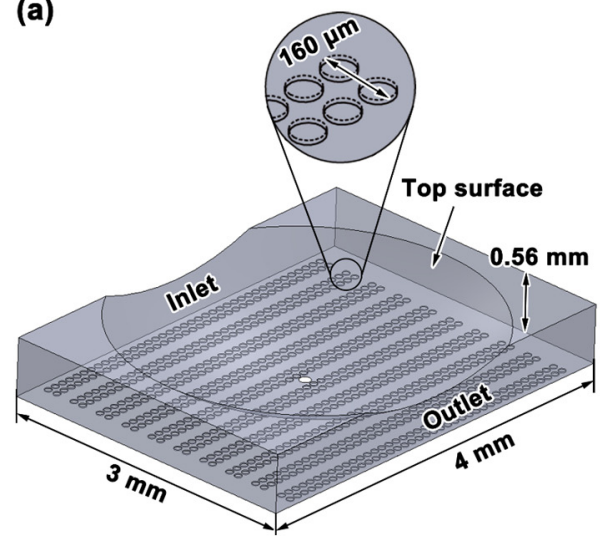

(b)

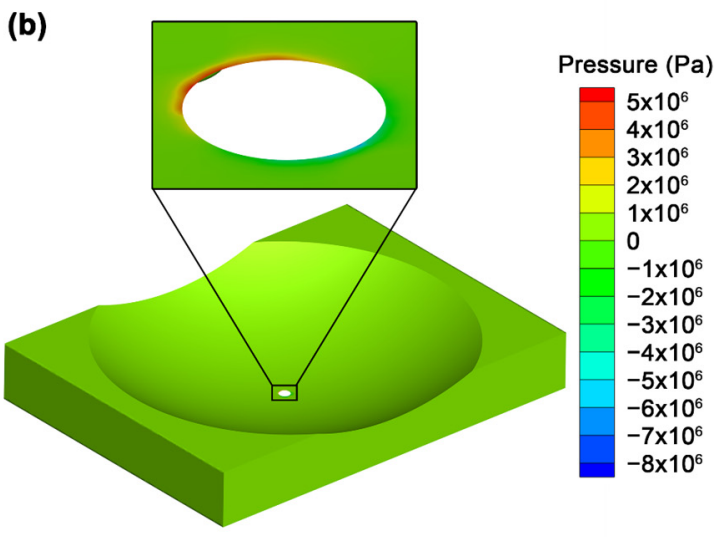

Figure 7. Schematic of (a) the flow domain of the CFD model and (b) the pressure distribution in the flow domain.

An open-source CFD code OpenFOAM was used in this study. The total element number of the flow domain mesh was $9.3 \times 10^{6}$. Due to the low sliding speed applied in the test, the cavitation was negligible in the simulation. Based on the Navier-Stokes equations, mass conservation Equation (6) and momentum conservation Equation (7) are shown as follows:

$$
\begin{gathered}
\nabla \cdot \boldsymbol{v}=0 \\
\rho(\boldsymbol{v} \cdot \nabla)=-\nabla p+\mu \cdot \nabla^{2} \boldsymbol{v}
\end{gathered}
$$

where $v$ is the velocity vector, and $\nabla$ is the Hamilton operator. The density of the engine oil $\rho$ was $850 \mathrm{~kg} / \mathrm{m}^{3}$, and the dynamic viscosity $\mu$ was $0.1422 \mathrm{~kg} / \mathrm{m} \cdot \mathrm{s}$ at $25^{\circ} \mathrm{C}$. The simulation result of pressure distribution is shown in Figure $7 \mathrm{~b}$. No pressure buildup occurred around the dimples, but a small high-pressure zone was observed around the contact zone. The high-pressure zone implied that the convergent form in sphere-flat contact may have contributed to the lubricant film formation rather than the proposed dimples.

\section{Conclusions}

This paper presents the performance of micro-dimpled texture using varied dimple densities under different normal loads and in dry and lubricated conditions. The microdimpled textures were fabricated using LST. Reciprocating sliding tests were conducted to determine if the micro-dimpled texture reduced friction under dry and lubricated conditions. The following conclusions were drawn from this study:

- For the lubricated condition, CoF decreased by $45.5 \%, 54.9 \%$, and $60.3 \%$ under normal loads of $6.5 \mathrm{~N}, 8.1 \mathrm{~N}$, and $11 \mathrm{~N}$, respectively; 
- For the dry condition, $\mathrm{CoF}$ decreased by $4.3 \%, 6.1 \%$, and $6.6 \%$ under normal loads of $6.5 \mathrm{~N}, 8.1 \mathrm{~N}$, and $11 \mathrm{~N}$, respectively. As the normal load increased, CoF increased in all non-textured and textured cases;

- Friction reduction is proportional to texture density. CoF showed a linear decrease as micro dimple density increased under dry and lubricated conditions;

- According to surface observations and the simulation, the dominant mechanism of the micro-dimpled effect on friction reduction could be the reduced contact area.

- For the friction reduction, the contribution of hydrodynamic pressure generation due to the micro-dimpled texture under lubricated conditions could be neglected according to the simulation result. Future surface texture design under high-pressure contact conditions could focus on the contact area rather than the lubricant flow mechanism.

Author Contributions: Conceptualization, Y.W. and J.R.; methodology, Y.W. and X.L.; investigation, Y.W. and R.T.; original draft preparation, Y.W. and X.L.; writing, review, and editing, R.T., J.R. and X.L. All authors have read and agreed to the published version of the manuscript.

Funding: The publication was funded by VINNOVA Sweden's Innovations Agency under the scientific research project nr 2017-05540 and start-up funds from Northwestern Polytechnical University G2021KY05112.

Acknowledgments: We would like to acknowledge Zhongtang Gao and Haibo Ren at the Xi'an University of Science and Technology, China for technical support.

Conflicts of Interest: The authors declare no conflict of interest.

\section{References}

1. Holmberg, K.; Erdemir, A. Influence of tribology on global energy consumption, costs and emissions. Friction 2017, 5, 263-284. [CrossRef]

2. Zhong, Y.; Zheng, L.; Gao, Y.; Liu, Z. Numerical simulation and experimental investigation of tribological performance on bionic hexagonal textured surface. Tribol. Int. 2019, 129, 151-161. [CrossRef]

3. Chang, T.; Guo, Z.; Yuan, C. Study on influence of Koch snowflake surface texture on tribological performance for marine water-lubricated bearings. Tribol. Int. 2019, 129, 29-37. [CrossRef]

4. Rosenkranz, A.; Costa, H.L.; Profito, F.; Gachot, C.; Medina, S.; Dini, D. Influence of surface texturing on hydrodynamic friction in plane converging bearings-An experimental and numerical approach. Tribol. Int. 2019, 134, 190-204. [CrossRef]

5. Sugihara, T.; Enomoto, T. Development of a cutting tool with a nano/micro-textured surface-Improvement of anti-adhesive effect by considering the texture patterns. Precis. Eng. 2009, 33, 425-429. [CrossRef]

6. Tala-Ighil, N.; Maspeyrot, P.; Fillon, M.; Bounif, A. Effects of surface texture on journal-bearing characteristics under steady-state operating conditions. Proc. Inst. Mech. Eng. Part J J. Eng. Tribol. 2007, 221, 623-633. [CrossRef]

7. Yin, B.; Xu, B.; Jia, H.; Hua, X.; Fu, Y. Experimental research on the frictional performance of real laser-textured cylinder liner under different lubrication conditions. Int. J. Engine Res. 2021. [CrossRef]

8. Zhang, J.H.; Chen, Y.; Xu, B.; Chao, Q.; Zhu, Y.; Huang, X.C. Effect of surface texture on wear reduction of the tilting cylinder and the valve plate for a high-speed electro-hydrostatic actuator pump. Wear 2018, 414, 68-78. [CrossRef]

9. Sinanoğlu, C.; Nair, F.; Karamış, M.B. Effects of shaft surface texture on journal bearing pressure distribution. J. Mater. Process. Technol. 2005, 168, 344-353. [CrossRef]

10. Wu, Z.; Bao, H.; Xing, Y.; Liu, L. Tribological characteristics and advanced processing methods of textured surfaces: A review. Int. J. Adv. Manuf. Technol. 2021, 114, 1241-1277. [CrossRef]

11. Etsion, I.; Burstein, L. A model for mechanical seals with regular microsurface structure. Tribol. Trans. 1996, 39, 677-683. [CrossRef]

12. Etsion, I. Increasing mechanical seal life with laser-textured seal faces. In Proceedings of the 15th International Conf on Fluid Sealing, Maastricht, The Netherlands, 16-18 September 1997.

13. Pettersson, U.; Jacobson, S. Influence of surface texture on boundary lubricated sliding contacts. Tribol. Int. 2003, 36, 857-864. [CrossRef]

14. Wan, Y.; Xiong, D.-S. The effect of laser surface texturing on frictional performance of face seal. J. Mater. Process. Technol. 2008, 197, 96-100. [CrossRef]

15. Hao, X.; Li, H.; Song, X.; Li, L.; He, N. Tribological Properties of Textured Cemented Carbide Surfaces of Different Wettability Produced by Pulse Laser. J. Micro Nano-Manuf. 2018, 6, 021001. [CrossRef]

16. $\mathrm{Hu}, \mathrm{J} . ; \mathrm{Xu}, \mathrm{H} . \mathrm{B}$. Friction and wear behavior analysis of the stainless steel surface fabricated by laser texturing underwater. Tribol. Int. 2016, 102, 371-377. [CrossRef]

17. Dai, F.Z.; Geng, J.; Tan, W.S.; Ren, X.D.; Liu, J.Z.; Huang, S. Friction and wear on laser textured Ti6Al4V surface subjected to laser shock peening with contacting foil. Opt. Laser Technol. 2018, 103, 142-150. [CrossRef] 
18. Schäfer, C.; Reinert, L.; MacLucas, T.; Grützmacher, P.; Merz, R.; Mücklich, F.; Suarez, S. Influence of Surface Design on the Solid Lubricity of Carbon Nanotubes-Coated Steel Surfaces. Tribol. Lett. 2018, 66, 89. [CrossRef]

19. Qiu, M.F.; Minson, B.R.; Raeymaekers, B. The effect of texture shape on the friction coefficient and stiffness of gas-lubricated parallel slider bearings. Tribol. Int. 2013, 67, 278-288. [CrossRef]

20. Liew, K.W.; Kok, C.K.; Ervina Efzan, M.N. Effect of EDM dimple geometry on friction reduction under boundary and mixed lubrication. Tribol. Int. 2016, 101, 1-9. [CrossRef]

21. Burlakova, V.E.; Tyurin, A.I.; Drogan, E.G.; Sadyrin, E.V.; Pirozhkova, T.S.; Novikova, A.A.; Belikova, M.A. Mechanical Properties and Size Effects of Self-Organized Film. J. Tribol. 2019, 141, 051601. [CrossRef]

22. Wang, X.L.; Liu, W.; Zhou, F.; Zhu, D. Preliminary investigation of the effect of dimple size on friction in line contacts. Tribol. Int. 2009, 42, 1118-1123. [CrossRef]

23. Yong, H.; Balendra, R. CFD analysis on the lubrication behaviours of journal bearing with dimples. In Proceedings of the 2009 International Conference on Mechatronics and Automation, Changchun, China, 9-12 August 2009; pp. 1279-1284.

24. Li, D.; Yang, X.; Lu, C.; Cheng, J.; Wang, S.; Wang, Y. Tribological characteristics of a cemented carbide friction surface with chevron pattern micro-texture based on different texture density. Tribol. Int. 2020, 142, 106016. [CrossRef]

25. Galda, L.; Pawlus, P.; Sep, J. Dimples shape and distribution effect on characteristics of Stribeck curve. Tribol. Int. 2009, 42, 1505-1512. [CrossRef]

26. Walker, J.C.; Cinti, S.; Kamps, T.J.; Mitchell-Smith, J.; Clare, A.T. Influence of contact area on the sliding friction and wear behaviour of an electrochemical jet textured Al-Si alloy. Wear 2019, 426, 1336-1344. [CrossRef]

27. Yagi, K.; Matsunaka, W.; Sugimura, J. Impact of textured surfaces in starved hydrodynamic lubrication. Tribol. Int. 2021, 154, 106756. [CrossRef]

28. Resendiz, J.; Egberts, P.; Park, S.S. Tribological Behavior of Multi-Scaled Patterned Surfaces Machined Through Inclined End Milling and Micro Shot Blasting. Tribol. Lett. 2018, 66, 132. [CrossRef]

29. Ghaednia, H.; Wang, X.Z.; Saha, S.; Xu, Y.; Sharma, A.; Jackson, R.L. A Review of Elastic-Plastic Contact Mechanics. Appl. Mech. Rev. 2017, 69, 060804. [CrossRef]

30. Butt, H.J.; Kappl, M. Surface and Interfacial Forces; John Wiley \& Sons: Hoboken, NJ, USA, 2018.

31. Wang, Y.; Dhong, C.; Frechette, J. Out-of-Contact Elastohydrodynamic Deformation due to Lubrication Forces. Phys. Rev. Lett. 2015, 115, 248302. [CrossRef] [PubMed]

32. Johnson, K.L. Contact Mechanics; Cambridge University Press: Cambridge, UK, 1987.

33. Guo, Y.B.; Liu, C.R. Mechanical Properties of Hardened AISI 52100 Steel in Hard Machining Processes. J. Manuf. Sci. Eng. 2002, 124, 1-9. [CrossRef]

34. Bowden, F.P.; Tabor, D. The Friction and Lubrication of Solids; Oxford University Press: Oxford, UK, 2001; Volume 1.

35. Yamamoto, T. Mechanism of friction and real contact area. JTEKT Eng. J. Engl. Ed. 2007. Available online: http://eb-cat.ds-navi. co.jp/enu/jtekt/tech/ej/img/no1003e/1003e_02.pdf (accessed on 15 December 2021).

36. Li, J.; Xiong, D.; Dai, J.; Huang, Z.; Tyagi, R. Effect of surface laser texture on friction properties of nickel-based composite. Tribol. Int. 2010, 43, 1193-1199. [CrossRef] 